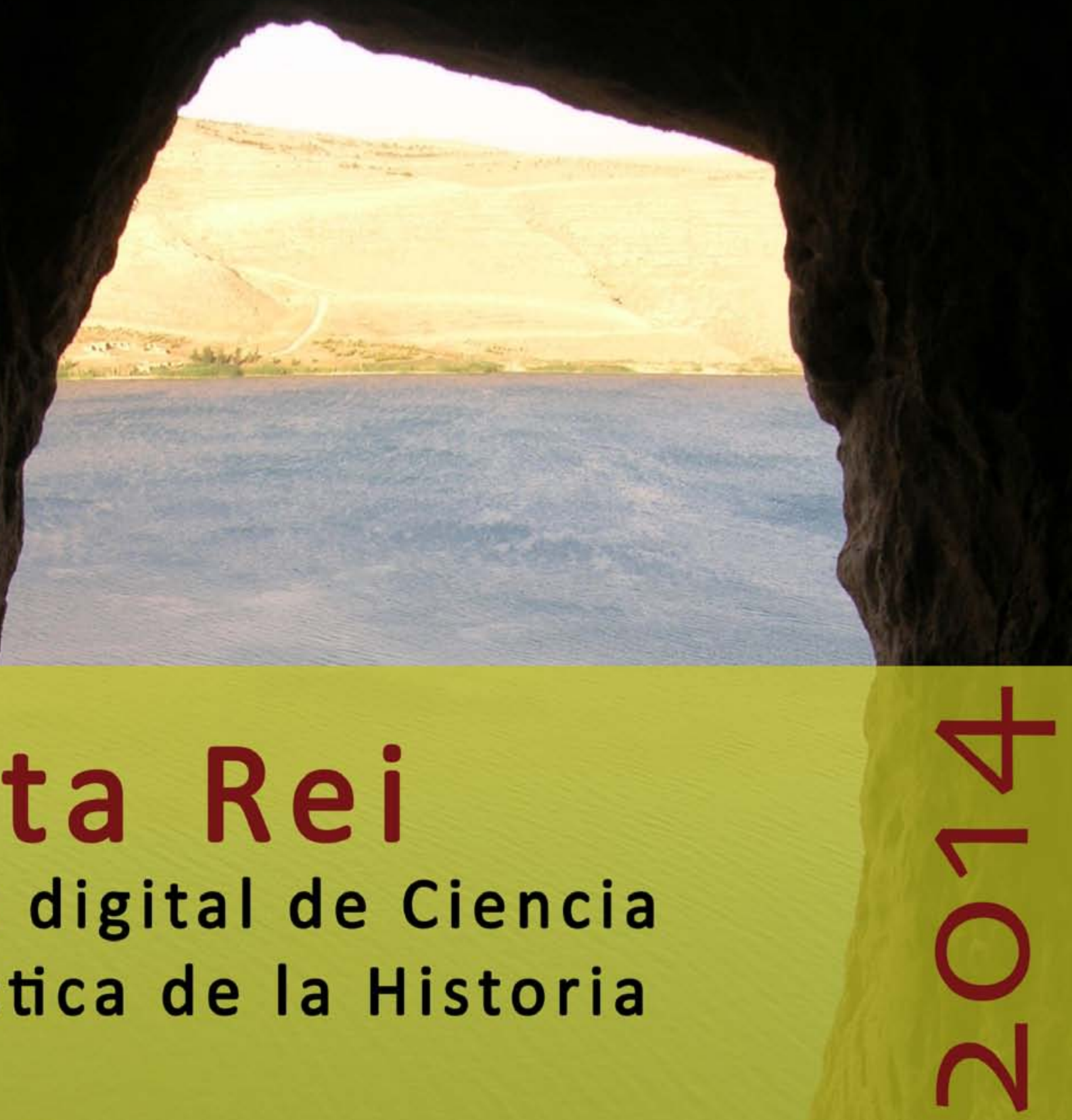





\section{Panta

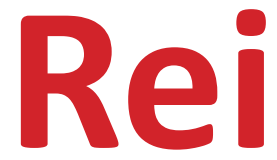 \\ Revista Digital de Ciencia \\ y Didáctica de la Historia}

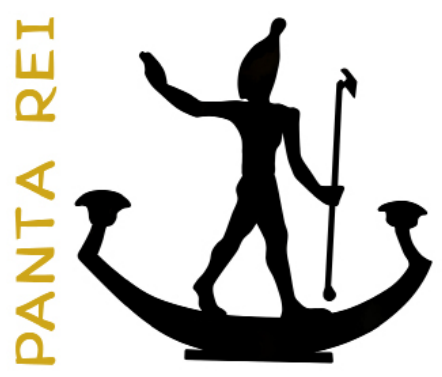

2014

Revista anual

Fecha de inicio: 1995

Revista Panta Rei. pantarei@um.es

\section{Edita:}

Centro de Estudios del Próximo Oriente y la

Antigüedad Tardía - CEPOAT

Edificio Universitario Saavedra Fajardo.

Universidad de Murcia

C/ Actor Isidoro Máiquez, 9

30007 - MURCIA - ESPAÑA

Teléfono: (+34) 868883890

cepoat@um.es

Web: www.um.es/cepoat/pantarei

Edición 2014

ISSNe: 2386-8864

ISSN: $1136-2464$

Depósito legal: MU-966-1995
cepoAt

UNIVERSIDAD DE MURCIA centro de estudios del próximo oriente y la antigüedad tardia

En Portada: Río Éufrates desde un eremitorio cristiano primitivo (Fotografía de Alejandro Egea).

Responsables de los textos:

Sus autores.

Responsable de la presente edición: Consejo Editorial Panta Rei. 


\section{CONSEJO DE REDACCIÓN}

\section{Coordinador editorial}

Egea Vivancos, Alejandro

[Didáctica de las Ciencias Sociales, UMU]

\section{Editores}

Botí Hernández, Juan Jesús

[CEPOAT, UMU]

Sáez Giménez, David Omar [CEPOAT, UMU]

\section{Secretaria}

Arias Ferrer, Laura

[Didáctica de las Ciencias Sociales, UMU]

\section{Responsable informático}

Martínez García, José Javier

[CEPOAT, UMU]

\section{Traducción y corrección lingüística}

Martínez Martínez, Cristina

[Sociedad Española de Lenguas Modernas]

\section{CONSEJO ASESOR}

Albero Muñoz, M. ${ }^{a}$ del Mar [H. ${ }^{a}$ del Arte, UMU]

Cobacho López, Ángel

[Derecho, UMU]

Egea Bruno, Pedro M. ${ }^{a}$

[Historia Contemporánea, UMU]

García Atienzar, Gabriel

[Prehistoria, UA]

González Monfort, Neus

[Didáctica de las Ciencias Sociales, UAB]

Haber Uriarte, María

[Prehistoria, UMU]

Irigoyen López, Antonio

[Historia Moderna, UMU]

Mahony, Simon

[Digital Humanities, UCL, Reino Unido]

Marsilla de Pascual, Francisco Reyes

[Técnicas historiográficas, UMU]

Miralles Maldonado, José Carlos

[Filología Clásica, UMU]

Molina Gómez, José Antonio

[Historia Antigua, UMU]

Noguera Celdrán, José Miguel

[Arqueología, UMU]

Pérez Molina, Miguel Emilio

[Filología Clásica, UMU]

Prados Martínez, Fernando

[Arqueología, UA]

Sánchez Ibáñez, Raquel

[Didáctica de las Ciencias Sociales, UMU]

Sancho Gómez, Miguel Pablo

[Educación, UCAM]

Vilar García, María José

[Historia Contemporánea, UMU] 
Presentación

Todo fluye. Renovarse y crecer

Alejandro Egea Vivancos, Laura Arias Ferrer, Juan Jesús Botí Hernández y David Omar Sáez Giménez

Artículos

La sociedad hiperbórea: ¿utopía o mito? Reflexiones acerca de la naturaleza y significado del relato hiperbóreo.

José Ángel Castillo Lozano.

Aproximación a la figura de una matrona romana culta y poderosa. El caso de Julia Domna.

Consuelo Isabel Caravaca Guerrero.

¡Arrasar la Vendée! Guerra Civil y Columnas Infernales en pleno corazón de la Revolución Francesa.

Benjamín Cutillas Victoria.....

Arte y expresión en el pensamiento de E. H. Gombrich.

Patricia Castiñeyra Fernández.

Odiseo a través de la parodia. Desmitificación e ironía de una Ítaca nostálgica en Prometeo de Pérez de Ayala y ¿Por qué corres, Ulises? de Gala.

Carmen María López López.

Análisis de la actividad didáctica del Museo de Arte Ibérico El Cigarralejo (Mula, Murcia).

Julio García Toral......

La Transición española en $4 .^{\circ}$ ESO. Un estudio de caso de los significados.

Borja Santiago Arnoso.

Entrevista

Entrevista al profesor D. Michael Walker.

Consuelo Isabel Caravaca Guerrero.

Reseñas

II Congreso de la Asociación Internacional de Investigación para la Educación de la Historia y las Ciencias Sociales.

Elvira Barriga y Rodrigo Salazar.

I Congreso de Jóvenes Investigadores del Mundo Antiguo de la Universidad de Murcia.

Pedro David Conesa Navarro

II Congreso Internacional de Educación Patrimonial.

Tània Martínez Gil.....

Ruiz-Gálvez Pliego, M. (2013). Con el fenicio en los talones. Los inicios de la Edad del Hierro en la cuenca del Mediterráneo. Barcelona: Editorial Bellaterra. 377 págs.

Celso Sánchez Mondéjar..

Normas de publicación/Publishing rules 



\title{
La sociedad hiperbórea: ¿utopía o mito? Reflexiones acerca de la naturaleza y el significado del relato hiperbóreo
}

\author{
Hyperborean's society: utopia or myth? Thoughts on the nature and \\ meaning of the hyperborean story
}

José Ángel Castillo Lozano

Universidad de Murcia

Eso que dices, hija, vale más que el oro,

y es mejor incluso

que una vasta suerte hiperbórea.

Esquilo, Coéforos 373

Recibido: 27/05/2014

Aceptado: 30/08/2014

Para citar este artículo: Castillo Lozano, J. A. (2014). La sociedad hiperbórea: ¿utopía o mito? Reflexiones acerca de la naturaleza y el significado del relato hiperbóreo. Panta Rei. Revista Digital de Ciencia y Didáctica de la Historia, 11-24.

ISSNe: 2386-8864

DOI: http://dx.doi.org/10.6018/pantarei/2014/2

\begin{abstract}
Resumen
En este artículo trataré los elementos que conforman el relato de los hiperbóreos presente en las fuentes antiguas. Estos elementos los podemos clasificar en dos grandes grupos: los elementos utópicos y los elementos míticos. A través del análisis de estos elementos, intentaremos averiguar exactamente cuál es la naturaleza de este relato y el sitio que ocupa en el imaginario colectivo del griego de la Antigüedad.
\end{abstract}

\section{Palabras claves}

Hiperbóreos, relato utópico, relato mitológico, mundo de las ideas y las creencias griegas.

\section{Abstract}

Throughout this article I will deal with the elements conforming the story of the Hyperboreans, present in ancient sources. We can split these elements into two big groups in order to arrange them: there are utopian elements and mythical elements. By analysing them, we will try to figure out which is the precise nature of this story, as well as the place where it belongs inside the collective imaginary of Ancient Greek.

\section{Key words:}

Hyperboreans, utopian narrative, mithological narrative, world of greek's beliefs and greek's ideas. 


\section{Introducción}

La mente del erudito griego siempre tuvo la tendencia a proyectar sus deseos a través de la creación de utopías, término con el que debemos llevar especial precaución pues como señalan Lens Tuero y Campos Daroca (2000), este concepto es un modo de escritura y de pensamiento tan característicamente moderno que al retrotraerlos a una literatura antigua que no puede sino desconocerlos en un sentido estricto, puede distorsionar nuestras conclusiones. El origen etimológico de la palabra utopía no fue del todo explicado por Tomás Moro, pero deja entrever un doble juego de significados, ambos del griego. Por un lado оúтопía (оú, nо; тóтоs, lugar que vendría a significar

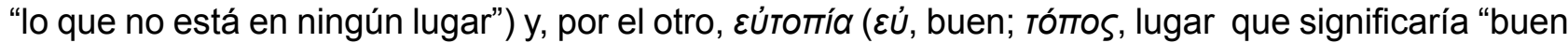
lugar"). Se podría indicar de esta manera que su significado sería algo así como: "un lugar que no existe" en la realidad pero en el que las personas reflejan sus más ardientes deseos y aspiraciones y, así, los convierte en "buenos lugares".

Estos lugares, básicamente, se contraponían a la situación que se vivía en la Grecia antigua, por ello, los habitantes de estas utopías solían vivir despreocupados y en unas situaciones óptimas e idílicas a través de una serie de posibilidades que muchas veces habían sido otorgadas como el favor de una divinidad con la que tenían una especial relación bien porque este dios hubiera nacido entre ellos o bien porque algún hecho entre este dios y esta comunidad hubiera provocado una estrecha relación entre ambas partes. Tal vez, este tipo de utopías siempre hubieran existido en el imaginario colectivo, sin embargo, los primeros que las pusieron por escrito serían Hesíodo en su obra Trabajos y días (109-202) y Homero ${ }^{1}$ al relatar la sociedad de los feacios (Od., canto XI). Podríamos decir que el ciego de Quíos y Hesíodo recogerían por escrito historias orales de leyendas, mitos y sucesos que plasmarían en sus obras y que estas, a su vez, servirían como modelo-guía al resto de los autores antiguos a la hora de otorgar una serie de características "dramatúrgicas" a los pueblos alejados de las poleis.

A partir de estos dos relatos, se configurarían una serie de lugares comunes que aparecen en esta geografía utópica griega como por ejemplo: el locus amoenus, tener buenas y abundantes cosechas o ser seres de ancestral sabiduría. Estas características especiales los diferencian desde el punto de vista etnográfico de las sociedades "reales" puesto que estas personas que desarrollaban su vida bajo el amparo de las directrices de una comunidad utópica poseían una serie de características totalmente idealizadas al compararlas con los atributos del griego de "a pie".

El género de las utopías clásicas ha sido agrupado por la historiografía en dos grandes grupos (Lens Tuero y Campos Daroca, 2000):

- La utopía de evasión, escapista o descriptiva, cuyo máximo ejemplo bien puede ser el conocido mito de la Edad de Oro del poeta griego Hesíodo o el logos hiperbóreo presente por primera vez en el libro IV de las Historias de Heródoto y cuyo análisis conformará el cuerpo central del presente ensayo. Este tipo de construcciones retóricas suponen una válvula de escape ante un tipo de situación problemática. Es significativo que las utopías acontecidas durante el renacimiento, también, se escriban en una situación de deterioro social y económico. Esto sucede porque estas construcciones fantasiosas, suponen un anhelo ante lo que no se posee y lo que se quiere tener.

- La utopía constructiva o política es la que viene amparada como modelo o programa de acción "político". Un ejemplo claro al respecto es el conocido mito de la Atlántida presente en las escritos Timeo y Critias de Platón. Las normas presentes en esta civilización son el paradigma

\footnotetext{
1 Aún admitiendo que Homero hubiese sido una persona real, lo cual no está nada claro, sin duda alguna habría sido un aedo que recitaba versos aprendidos oralmente. También cabe la posibilidad de que pudiera tratarse de un conjunto de distintas personas que fueran poniendo por escrito distintas tradiciones que hundirían sus raíces en tiempos prehistóricos. En cualquier caso, en este trabajo, metodológicamete, hemos optado por asignar a Homero la escritura de estas obras aunque esta autoría esté en tela de juicio por la historiografía actual.
} 
de la justicia pues el estado ideal es el que garantiza esto: una justicia proverbial y divina. Hemos introducido otro concepto, el de justicia divina pues las normas que regulaban la vida en la Atlántida las había realizado Poseidón y se encontraban grabadas sobre una columna de oricalco².

Tras esta breve introducción pasamos al verdadero objetivo de nuestro trabajo: el estudio y comprensión del relato hiperbóreo presente en las fuentes antiguas con especial énfasis en el excurso que pronuncia Heródoto en su IV libro ${ }^{3}$.

\section{La sociedad hiperbórea y su localización}

Las referencias a Hiperbórea, el país donde habitaban los hiperbóreos, son numerosas. Las primeras referencias, hipotéticamente, están en Hesíodo y en los Epígonos de Homero tal y como nos muestra el llamado padre de la historia (Hdt, IV, 32). Por este motivo, el origen de esta comunidad hiperbórea pueda remontarse a una época tan lejana donde, incluso, la escritura aún no había hecho acto de presencia (Harmatta, 1957). Aunque el primer literato en realizar una cita de este pueblo relativamente amplia fue Heródoto. A partir de él, tenemos numerosas referencias de este pueblo en Píndaro, en Plinio, en Hecateo de Abdera, que posee una obra que se titula Sobre los Hiperbóreos ${ }^{4}$ de la que se nos han conservado ocho fragmentos (FgrHist 264 T 6), en Diodoro Sículo gracias al cual se mantiene viva (o al menos nos ha llegado a nosotros, los historiadores) la obra Sobre los hiperbóreos de Hecateo de Abdera pues bebe directamente de esta tradición, etc.

En estas referencias, dicho país se toma como algo lejano, en los límites de la ecúmene (Albaladejo Vivero, 2005), aunque cierto ${ }^{5}$. Habitan en un topos tan lejano que solo pueden llegar a él dioses como Apolo, héroes como Hércules o Perseo que se enfrentó en este territorio contra las gorgonas (Graves, 2001), personajes míticos como Midas (Graves, 2001) o seres mortales ungidos por los dioses como Creso. Este suceso del rey de Lidia muestra ciertos elementos escatológicos ${ }^{6}$ (Gómez Espelosín, 1997) ya que este rey llegará al hogar de los hiperbóreos debido a la compasión

2 Un elemento primordial y, por ende, sagrado al igual que aquel lugar donde se encuentra: la cueva. Dicha apreciación ha sido estudiada por Eliade (2001) y Molina Gómez (2006 y 2007).

3 Dicha fuente será complementada con otras fuentes literarias. El objetivo de este trabajo es realizar un preámbulo para alguna clase de estudio de mayor amplitud que abarque la totalidad de fuentes de este pasaje y, por qué no, una exhaustiva comparación con otros pasajes de esta naturaleza.

4 Una obra que seguramente tuviera una doble vertiente: una vertiente etnográfica e, incluso, ética basada en la utopía, y otra literaria a modo de entretenimiento siguiendo el modelo de Las Historias Verídicas de Luciano de Samosata (Caballero López, 2010)

5 Pindaro nos señala la imposibilidad de llegar al territorio donde habitaban esta lejana y diferente comunidad. En su obra Píticas (X, 27), nos apunta esta idea, sus palabras exactas son las siguientes: "ni yendo en navíos ni a pie, encontrarás el maravilloso camino a las reuniones de los hiperbóreos".

6 Estos lugares alejados de la ecúmene también se prestan para la neukia que es un rito relacionado con la catábasis y anábasis. Otra vez Homero nos da prueba de ello en su canto XI cuando Odiseo desciende al al reino de Hades. La idea homérica sobre la vida sombría de las almas de los muertos emerge como resignación (Rohde, 1983), así el ciego de Quíos pone estas palabras en los labios de Aquiles "el de los pies ligeros": "nadie hay que no prefiriese vivir esclavo de un campesino pobre a gobernar en todo el Tártaro" (Od., $\mathrm{XI}$ ). En los poemas de Homero, también, observamos un proceso de ritualización de la muerte, de asentar una serie de condiciones para que el viaje fuera óptimo y que el muerto pudiera reposar y no vagar entre el limbo de los vivos y los no-vivos. Estas palabras que pronuncia Patroclo a Aquiles, en el transcurso de un sueño del héroe mirmidón, son un reflejo ideal de lo que se ha intentado reflejar en las anteriores líneas: "Entiérrame cuanto antes, para que pueda pasar las puertas del Hades; pues las almas, que son imágenes de los difuntos, me rechazan y no me permiten que atraviese el río y me junte con ellas; y de este modo voy errante" (II., XXIII). También encontramos esta idea en unas líneas más tardías que se localizan en la obra de Virgilio: "No es permitido atravesar estas hórridas riberas y la ronca corriente, antes que sus cenizas descansen en sus sepulcros. Andan errantes cien años revoloteando en torno a estas riberas" (Eneida, canto VI). Para finalizar, vemos como el lugar donde se puede desarrollar este cosmos de creencias e ideas se ubica en un lugar lejano de la Grecia "corpórea". 
de Apolo que lo salvará de la pila funeraria y llevará al depuesto rey a aquel lugar donde recibía las mayores ofrendas y honores. Por lo visto hasta ahora, vemos que los meros mortales eran incapaces de llegar a las tierras situadas en los límites de la ecúmene, por ende, eran los lugares óptimos para desarrollar este tipo de hechos, sucesos o relatos fantásticos.

La cuestión de su localización geográfica es muy complicada por su lejanía y se introduce dentro de los itinerarios de lugares míticos que nos comenta Gómez Espelosín (2000). La propia etimología de la palabra "hiperbóreos", nos dice que viven más allá del viento Bóreas, es decir, en algún lugar lejano y desconocido localizado en el norte (Dion, 1976).

Heródoto nos habla de un tal Aristeas de Proconeso ${ }^{7}$. El padre de la historia se basó en gran medida en el testimonio poco fiable de este oscuro y desconocido personaje de cualidades chamánicas (Gómez Espelosín, 1997) que supuestamente dio muestras de haber intentado llegar hasta el confín donde habitaban estos hiperbóreos en su poema Arimaspeas. Su relato (si verdaderamente existió) fue resumido brevemente por el padre de la historia y, asimismo, fue utilizado por autores posteriores que beberían de la tradición iniciada por Heródoto. Este extraño individuo que infundido por un éxtasis apolíneo (era seguidor de Apolo) viajó hasta la tierra de otro desconocido pueblo (los isedones). Este pueblo le contará que más allá de una alta cordillera y a la orilla de un mar, habitaba una increíble y aventajada raza de hombres: los hiperbóreos (Hdt, IV, 13). A la hora de describirnos los vecinos de los escitas (Hdt, IV, 21-27), habla del río Tánais, en una dirección noroeste. En relación a esto, se puede llegar a decir que Aristeas sitúa a esta raza privilegiada en la zona del macizo del Altai. A su vez, este relato supone una de las estrategias de veracidad por parte del historiador de Halicarnaso para dotar de autenticidad a su escrito como veremos a continuación.

Autores como Heródoto no estaban plenamente convencidos de su realidad física, aunque otros como Plinio sostenían que era imposible dudar de su existencia $(H N 4,12,88)$. En cualquier caso, el padre de la historia realizará una serie de estrategias para dotar de veracidad al relato y así alejar su obra de los relatos sobre cosas sorprendentes (tà thaumásia) tan comunes a los logógrafos y al propio Heródoto aunque este se esfuerce en no padecer dicha impronta, a pesar de su intento, su empeño será en vano pues no será muy bien visto por la historiografía antigua ${ }^{8}$ debido a la concepción de la figura del historiador que debe contar los hechos que suceden a su alrededor que impuso Tucídides en su obra Historia de la guerra del Peloponeso. Estas estrategias consisten en: inmiscuir a un tal sacerdote de nombre Abaris (Hdt, IV, 36) que vivió entre ellos y luego viajó por todo el mundo predicando acerca de Hiperbórea como si de una tierra prometida se tratara; indicar que realizaban asombrosas ofrendas envueltas en paja de trigo (símbolo de abundancia) a Apolo y explicaba su ruta, además, de unas muchachas de nombre Hipéroque y Laódice que fueron las primeras en llevar las ofrendas al santuario de Delos (Hdt, IV, 33-35) o indicar su carácter pacificador sobre otros pueblos (Hdt, IV, 13). De esta forma, Heródoto evitaba inmiscuirse en el campo de la fábula y de la simple invención hechos, sucesos sobrenaturales y taumatúrgicos con la "racionalización" del mito (Albaladejo Vivero, 1998).

De esta forma este territorio se ubicaría como hemos mencionado anteriormente en los confines nororientales de la ecúmene, más allá de los montes Ripeos ${ }^{9}$ que los aislaban del frío de Bórea y del resto de pueblos. Esto es muy importante porque apunta al factor de aislamiento para no "mezclarse" y "contaminarse" con el resto de pueblos y mantener sus condiciones primigenias intactas y puras. Por añadidura, y para potenciar este concepto, dicho pueblo se situaba en torno al

7 En esta obra se hace un completo estudio de la figura de este Aristeas que nos menciona el escritor oriundo de Halicarnaso (Bolton, 1999).

8 Para ver la valoración y acogida de la obra de Heródoto en la antigüedad, consultar la obra de Caballero López (2010).

9 Existe un debate acerca de si vivían en estos montes, más allá de este accidente geográfico o a las lomas de estos (Albaladejo Vivero, 1998). En cualquier caso, lo importante es el factor de aislamiento que proporcionan a este pueblo y que les proporciona unas características peculiares a esta comunidad. 
océano, otro factor que influye en su idealización ya que está presente una idea de alejamiento de la Hélade que supone una difusión de formas que favorece la introducción de elementos fantásticos $y$, dentro de estos, de elementos utópico. Vemos, en consecuencia, que está latente un temor o, mejor dicho, un desconocimiento palpable de los viajeros a la hora de adentrarse a las zonas marginales ("eschatiai") que rodeaban a la Hélade, territorio civilizado y ordenado por la "polis" (Gómez Espelosín, 2000).

En cierta manera, su ubicación geográfica recordaría a la de los feacios en la Odisea (canto V) o a cualquier otro pueblo de estas características pues, como apunta Gómez Espelosín (2000), cuando uno se adentra en un itinerario mítico que discurre por un espacio puramente imaginario y fantástico, se pierden las referencias explícitas a la geografía real aunque sí se den apuntes geográficos para dotar de una mayor verosimilitud al relato. $Y$ esto es justamente lo que nos encontramos en el pasaje hiperbóreo de Heródoto ya que este historiador-geógrafo- etnógrafo no nos da referencias "reales" aunque si nos menciona a distintos pueblos poco o nada conocidos (Hdt, IV, 13) como eran: los escitas (único pueblo "real"), los isedones que eran un pueblo del que se contaba que se comían a sus muertos, la peor cualidad que le podía atribuir un griego clásico a un bárbaro: el canibalismo, sin embargo, Heródoto ${ }^{10}$ nos señala que era un pueblo justo y que sus mujeres tenían los mismos derechos que los hombres (una concepción algo negativa en el imaginario del griego de la antigüedad); los arimaspos, otro pueblo fantástico cuyas gentes tenían un ojo y luchaban con los grifos para mantener el oro que extraían de unas madrigueras. Éste es un buen ejemplo del topos que enfrentaba al ser humano con la naturaleza, en concreto, con los animales (Albaladejo Vivero, 1998). Finalmente, Heródoto hace referencia a unos animales sobrenaturales que eran los grifos cuya función era custodiar el oro. Estos pueblos son portadores de los atributos "bárbaros" fruto de la retórica de la alteridad griega que componen las afiladas plumas de los escritores griegos clásicos. Más allá de estos pueblos bárbaros habitarían nuestros hiperbóreos al lado de un inmenso mar que a su vez generaría otra barrera para su idealización.

Un aspecto muy interesante que les sucede a estos hiperbóreos al compararlos con otros pueblos extranjeros es que no se le asignan tópicos bárbaros en ningún momento, a pesar de estar alejados de la Hélade, al contrario que pasaba con el ejemplo paradigmático de barbarismo para el mundo griego: el mundo persa ${ }^{11}$. Ante esta tesitura recién explicada, observamos cómo la Hélade se convertiría y actuaría como el hipotético centro de cultura y civilización para un griego. Esta teoría se ha venido definiendo como la teoría de "círculos concéntricos ${ }^{12 "}$ y su desarrollo consiste en que la cultura y la civilización se desarrollan en exclusiva en la Hélade y, a medida que nos alejamos de ella, va aflorando la barbarie aunque con este pueblo vemos cómo se ha producido un proceso radicalmente opuesto. Dicho tratamiento literario podríamos definirlo como un etnocentrismo inverso, mostrándonos a esta comunidad como un pueblo civilizado a pesar de encontrarse en los confines de la ecúmene y que nos recuerda, en cierta manera, a esos famosos gimnosofistas indios que Alejandro Magno visitó por lo afamado de su sabiduría.

10 También debemos ser cautelosos pues Heródoto ha sido llamado el padre de la antropología cultural por el siguiente pasaje donde nos cuenta como Darío I como el gobernante ideal que es, no tiene prejuicios ante distintas creencias y así lo hace ver: "En cierta ocasión hizo llamar Darío a unos griegos, sus vasallos, que cerca de sí tenía, y habiendo comparecido luego, les hace esta pregunta: —cuánto dinero querían por comerse a sus padres al acabar de morir. - Respondiéronle luego que por todo el oro del mundo no lo harían. Llaman inmediatamente después a unos indios titulados Calatias, entre los cuales es uso común comer el cadáver de sus propios padres: estaban allí presentes los griegos, a quienes un intérprete declaraba lo que se decía: venidos los indios, pregunta Darío cuánto querían por permitir que se quemaran los cadáveres de sus padres; y ellos luego le suplican a gritos que no dijera por los dioses tal blasfemia. ¡Tanta es la prevención a favor del uso y de la costumbre!" (Hdt, III, 38). Sin embargo, erraríamos al pensar que Heródoto no dibuja a los pueblos extranjeros con distintos tópicos y atributos para diferenciarlos del griego.

11 Un estudio que trata el tema de la alteridad griega en el mundo persa es el de García Sánchez (2009).

12 Un esbozo de esta teoría aparece en Vernant (1992). 


\subsection{La isla como topos de la civilización hiperbórea. La isla de la utopía}

En este apartado veremos una interesante y diferente versión de esta narración que ubica a este lejano pueblo en un lugar geográfico que juega un papel fundamental en el imaginario colectivo griego. Este topos es la isla y el informador de este apasionante aspecto será Diodoro (que bebe de la obra Sobre los hiperbóreos de Hecateo de Abdera $^{13}$, s. III a. C.) ya que el historiador siciliano desvinculó a los hiperbóreos del extremo septentrional del mundo, más allá de los escitas y otros pueblos, para situarlos en una isla. De esta forma, Diodoro Sículo nos ubica este pueblo en una isla de tamaño parecido a la de su Sicilia natal y de nombre Helixoia que se situaría en la vertiente norte del océano exterior.

Este espacio geográfico se define como: "l'île (nèsos) se définit par opposition au continent (èpeioros)" (Vilatte, 1991, p. 15) y cumple la misma función que la que cumplirían los montes Ripeos que es la de aislar ya que en este territorio virgen, el ser humano no se corrompía y mantenía su condiciones primigenias sin contaminar, sin empozoñar por el contacto con otras poblaciones humanas. De igual modo, será el poeta Homero quien recoja una serie de tópicos que circularían en torno a la isla y los plasmaría en su Odisea. Como argumenta el investigador Vilatte (1991, p.15): "Calypso vit dans une île(...) le domaine de Circé est franchement insulaire comme celui d'Eole; chez les Cyclopes existe une lle petite. Mais le pays des Lotophages, celui des Lestrygons, la Cyclopie et, enfin, cas plus remarquable, la Phéacie ${ }^{14}(\ldots) "$.

De igual forma hemos de incidir en el hecho de que la isla está rodeada de agua. Esto lo hacemos pues dicho elemento es de vital importancia para dotar de significado al propio concepto de isla ya que el agua ocupa un espacio primordial en el imaginario colectivo como medio para deformar y crear cosas, como un recurso clave en sus ritos y creencias. No hemos de olvidar que los griegos consideran que son hijos del agua, todo se lo deben al mar, un mar que a su vez le puede arrebatar su más preciado bien, la vida, ya que en este aspecto el ítem agua juega un papel esencial en lo escatológico, en el viaje que emprende Caronte y las atormentadas almas humanas que adquieren la categoría del eidolon (Díez de Velasco, 2010). De este modo, el mundo griego antiguo, hijo del agua, puebla con ella sus fantasías y explica sus orígenes y su final, así como el estado de las cosas a través de corrientes (Rudhart, 1971) defendiendo su ambivalente estado actuando a la vez como destructora y creadora, siendo esto una dualidad muy presente en el mundo de las creencias griegas.

De igual modo, toda isla cuenta con una serie de elementos comunes como son: una playa, pueden llegar a tener algún puertos y, normalmente, en su centro suele haber algún tipo de montaña (Vilatte, 1991 y Peyras, 1995). Esto es muy interesante porque normalmente el habitante o ser fabuloso que habita la isla lo hace en una especie de palacio en el centro de la isla, localizado normalmente entre montañas, o en alguna cavidad de la montaña o montañas. Tenemos un gran número de prototipos de ello que empieza a desarrollar Homero que localiza a sus sociedades y seres ideales en estos accidentes orográficos. Por ejemplo, la maga Circe vivía en un palacio o, en la Ilíada, los aqueos van a recoger a Filoctetes que habitaba en una cavidad/cueva del acantilado de la isla de Lemnos por petición de Calcante pues su participación era esencial para alcanzar la victoria frente a los troyanos. Esto es muy interesante pues la montaña es de piedra/roca, un elemento puro y primordial con unas connotaciones mágicas y rituales muy fuertes como se ha puesto de manifiesto anteriormente. Por lo tanto, lo que estamos viendo es una construcción cósmica tal y como apunta también Vilatte (1991, p. 18): "L'île, dans le monde imaginaire ou dans le monde réel, est la réduction d'une situation à l'échelle cosmique: construction en miroir (...)".

13 Autor que parece dar un nuevo horizonte a esta civilización elaborando una serie de datos ad hoc (Piquero Rodríguez, 2011). De esta manera, parece que nos encontramos un nuevo desarrollo del mito claramente orientado a configurar una nueva realidad que siglos después, Tomás Moro, llamaría la "Isla de la Utopía".

14 En La Odisea no se dice exactamente que sea una isla, pero su descripción y características si se acoplan a un ambiente insular (Vilatte, 1991) 
Además la isla siempre fue en el imaginario y en la retórica griega un lugar fantástico donde relegar a sociedades fantásticas (como es nuestro caso) o al que relegar a seres semidivinos o de carácter extraordinario y monstruoso (Gómez Espelosín, 2007; Gómez Espelosín, Guzmán Guerra y Guzmán Gárate, 2005; Rudhart, 1971; Peyras, 1995 y Vilatte, 1991) y es que si nos ponemos a comprobar, la mayoría de los dioses del Olimpo tienen algún tipo de relación con alguna isla: Zeus nació en Creta (también hogar del mítico Minotuaro, a partir del cual se enlaza con otros personajes heroicos como Dédalo, Teseo o el rey Minos); Apolo tiene una íntima relación con Delos que significa "visible" pues antes de que los isleños aceptaran el culto al dios del sol, recibía el nombre de Adelos que significa "invisible" (Martínez Hernández, 2010); Hefesto vive en Lemnos; Afrodita vive en Chipre, etc. Lo mismo sucede con los héroes, así nos encontramos las aventuras de los argonautas, sucesos relacionados con Teseo (cuando acude a Creta o abandona a la joven Ariadna en un pequeño peñón insular), la vuelta a casa de Odiseo pasando por las islas de los feacios o de Circe entre otras, etc.

Así, el concepto de Diodoro es similar al anterior, un lugar aislado donde se desarrolla de forma primigenia un pueblo con características utópicas. Diodoro recoge la tradición de Hecateo de Abdera, como hemos señalado, que ya situaba a este pueblo utópico en una isla en el océano frente a los territorios celtas y "más allá" (hyper-) de donde se origina el viento del norte (Bóreas). Esto no ha de extrañarnos pues la retórica griega siempre guardó un especial lugar para las islas.

Siguiendo con el hilo de la isla como lugar/residencia donde localizar a pueblos de características utópicas e ideales, debemos fijarnos con especial atención a la que realizó Tomás Moro ${ }^{15}$. La sociedad que desarrolla este autor inglés se situaba en una isla y el pueblo que la habitaba estaba organizado por unas leyes de magnánima justicia gracias a las cuales no había guerra y todo se desarrollaba en paz, armonía y justicia por la bondad de Dios. Dicha utópica sociedad (que se podría relacionar con los dos grandes tipos de utopías que vimos en la introducción) esta alejada de una sociedad consumida en una crisis por la ambición de sus gobernantes que se disputaban cada palmo de tierra por y para su gloria personal pero que nada hacían por solucionar y evitar el sufrimiento que su pueblo soportaba por estos enfrentamientos. Por consiguiente, vemos cómo crear civilizaciones utópicas en el imaginario concuerda con unas circunstancias puntuales y que reflejan justo lo contrario de la época que les ha tocado vivir a sus autores y que se crean respetando unos lugares comunes que se respetan en todas ellas para conservar su naturaleza y función.

Debemos señalara a modo de conclusión cómo la isla es un "alter orbis" que, al estar aislado, es desconocido por el griego y, en consecuencia, es el ambiente ideal para dar forma y/o proyectar las ideas y creencias presentes en el imaginario del griego de la Antigüedad.

\section{Elementos utópicos del relato}

Como ya hemos venido mencionando a lo largo del presente estudio, esta mítica civilización, de discutida existencia, ha venido recibiendo una serie de atributos que son habituales en los pueblos utópicos que localizan su actividad y su existencia en los confines del mundo conocido. Estas características son: su naturaleza pacífica (Hdt, IV, 13: 'todas estas naciones según él, exceptuando solamente los hiperbóreos, estaban siempre en guerra con sus vecinos"); la gran fertilidad de sus tierras gracias a un clima perfecto fruto de la vida bajo un cielo siempre puro y consagrado a Apolo; longevidad de estas gentes superior a lo que consideraríamos una longevidad "natural" para un ser humano; la posesión de un sistema político ideal y una justicia proverbial que desciende de las propias divinidades, en este caso, es Apolo quien le otorga a esta comunidad sus propias leyes actuando como si de un héroe civilizador y legislador se tratara ya que aparte de las

15 Un autor que sin duda tuvo que ser consciente de la existencia de las utopías clásicas a la hora de confeccionar su obra y es que durante el periodo renacentista se produjo un "redescubrimiento" del mundo antiguo por lo que no debe extrañarnos determinados ecos de autores antiguos en esta Utopía de Tomas Moro o en otros escritos de esta época. 
leyes les otorga también, entre otras cosas, unas pautas de comportamiento y una serie de creencias ritualizadas; la presencia en sus tierras de elementos tan lujosos como el ámbar que no es sino una prueba de su extremada riqueza; la ausencia de trabajo y, en consecuencia, el transcurso de una vida plácida y tranquila que hacía que sus gentes se dedicaran a la danza y a la música como en el ideal de paideia griega (Piquero Rodríguez, 2012); una relación íntima con la naturaleza como el episodio donde unos cisnes blancos (aves consagradas a Apolo) aparecen cantando junto con estos habitantes de Hiperbórea en honor a Apolo; estrecha relación con los dioses sobre todo con Apolo de quien se dice que su madre, Leto, pertenecía a este pueblo o al menos había nacido entre ellos, además de que Apolo cuando nació pasó un año entre ellos y cada año, durante los meses de invierno, se refugiaba entre ellos para escapar de la hostilidad del tiempo pues el lugar donde vivían los hiperbóreos siempre gozaba del mejor de los climas; tenían, a pesar de la abundancia, una vida austera que era una pretensión/ideal del mundo griego clásico (Vernant, 1992) que se había perdido y que ya se encontraba alejado, dicho ideal, de los desmanes que protagonizaban determinadas poleis griegas fruto de la hybris de sus gobernantes, etc.

Todas estas características se cumplen en los relatos de estos lugares que poseen esta tipología de "pueblos utópicos" (Ferguson, 1975 y Gómez Espelosín, Pérez Largacha y Vallejo Girvés, 1994). Vamos a hacer la prueba de compararlo con el conocido logos de Arcadia presente en la obra de Pausanias (Descripción de Grecia, VIII), en la de Estrabón (Geografía, VIII, 8) y en la de Heródoto (Historias, I). Ambas son tierras que proporcionan grandes cosechas y albergan grandes riquezas fruto, en gran parte, por la inmensa fertilidad de su tierra (eukrasia) que no hemos de olvidar que es debida gracias al don de uno o varios dioses. Gracias a esto, los pobladores pueden dedicarse a otros menesteres que no son el duro trabajo de la tierra y, por ello, estos habitantes desarrollan un talento hacia la música y hacia el trato de los dioses que complementan con un carácter dócil y benevolente pues están amparados bajo una ley divina que se complementa con este carácter pacífico lo que hace que desemboque en una vida pacífica y llena de dichas, justo lo contrario de lo que pasaba en un "mundo real" enfrascado en las siempre difíciles relaciones diplomáticas entre las distintas poleis. Además, en ambas tierras, perviven las "huellas visibles de los dioses y héroes" (Gómez Espelosín et alii, 2005, p. 170) ya que ambos lugares serán el escenario donde los dioses nazcan y pervivan en sus primeros años de vida (Hermes, Zeus y otras divinidades por parte de Arcadia, y Apolo por parte de Hiperbórea) y ambas serán los escenarios de las valerosas e increíbles acciones de los héroes. Así, en Arcadia, Herácles deberá enfrentarse al jabalí Erimanto y a las aves carnívoras de la laguna Estinfalia mientras que en el país de los hiperbóreos este héroe griego deberá capturar a la cierva de Cerinea.

De igual modo podemos decir sin miedo a equivocarnos que muchos de estos rasgos que se aplican a los hiperbóreos son similares a los que la tradición escrita griega asigna a otros pueblos utópicos y situados en los confines de la tierra. En concreto, me gustaría incidir que todos estos atributos coinciden punto con punto con lo que Hesíodo nos habla de lo que era el ser humano durante la llamada Edad de Oro (Trabajos y Días, 106) por lo que se pone de manifiesto que fue este poeta y ese desconocido elenco de autores que aparecen bajo el nombre de Homero quienes pusieron por escrito unas tradiciones orales previas acerca de estas utopías. Además, no hemos de olvidar que el hombre de la Edad de Oro estaba más próximo a los dioses con los que compartía un origen común pues el hombre había sido engendrado por la tierra (gegenesis) y los dioses habían sido originados de Gea (Eliade, 1999). Gracias a esto, los hombres gozaban del favor directo de los dioses y eran amigos de estos, sin embargo, con el progresivo deterioro del género humano, esta relación se fue deteriorando y perdiendo hasta llegar a lo que el propio poeta griego Hesíodo decía: “¿Qué desgracia la mía, haber nacido en esta edad, en la quinta generación!" (Rohde, 1973, p. 56). Debido a esta "involución" el ser humano fue dejado de lado por los dioses menos estos "semidivinos" (sería más preciso decir "puros") hiperbóreos que gracias a su aislamiento con el resto de la raza humana, mantenían estas características naturales y primordiales intactas.

Esto nos puede estar indicando un proceso desde una óptica un tanto crítica, es decir, en un terreno distante, aislado y virgen, la sociedad humana ha vivido tal y como fue concebida. Esto se 
pone en contraposición a las penurias, hambrunas, guerras, etc., que suceden en el resto del mundo y es que, tal y como sostiene Gómez Espelosín (1997, p. 452): "la mirada del griego hacia el exterior era del todo interesada. Incapaz de salir de sí mismo, no hacía otra cosa que trasladar allí sus propias preocupaciones acerca del hombre o de la sociedad". Por lo tanto, no podemos tomar este relato de los hiperbóreos como algo lejano de la civilización griega sino, debemos tomarlo, como parte de su imaginario, como un reflejo de su pensamiento desarrollado en este lejano cosmos.

Ante el contexto al que hemos hecho referencia, a nuestro juicio, creo que a través de este relato presente en las fuentes literarias puede estar introduciéndonos una sutil crítica a la naturaleza del ser humano, al contraponer dos estilos de vida tan distintos entre sí y que pueden estar en relación con el objetivo de Heródoto de hacer un tipo de historia de carácter moralizante. La propia obra de Hesíodo nos muestra un carácter pesimista donde el hombre se va degradando constantemente en una suerte de concepción cíclica de la historia que también se encuentra en el ejercicio literario del sabio de Halicarnaso (Caballero López, 2010).

Comprobamos de igual forma que esta unión a través de lo opuesto entre realidad y utopía se convierte en la conducción de la evolución, en la medida de que se aspira a esto pero, también, se convierte en la involución del género humano que tan bien se nos refleja en la obra de Hesíodo y que se refleja en este pasaje de igual forma. Esto está, de la misma forma, en relación con una idea que desarrolla Platón en su libro III de su República. Esta idea consiste en el concepto del mito como una serie de construcciones que manipulan la tradición oral de una determinada sociedad para lograr expresar una serie de ideas que en muchas ocasiones son de naturaleza crítica hacia lo que estaba sucediendo y se estaba desarrollando en sus días. El pasaje de Hesíodo de la raza de oro, servirá como modelo a seguir por aquellos autores que generen en sus escritos pueblos de este carácter, y responde también a una función escapista donde se sitúa una civilización ideal, similar a los dioses, en contraposición a la situación contemporánea.

A su vez, y para finalizar esta idea, este fenómeno responde a un estado natural del ser humano a considerar los tiempos pasados como algo mejor, en consecuencia, no ha de extrañarnos que el pasaje de la Edad de Oro, del que luego tomará sus atributos pueblos como el hiperbóreo, tenga una naturaleza popular, dejándose llevar este poeta por la tendencia de la fantasía a grabar en la memoria solamente los rasgos agradables del pasado contados por poetas o historias populares (Rohde, 1973).

\section{Elementos míticos del relato}

En este apartado vamos a analizar el otro gran grupo de los elementos que conforma la historia del mundo hiperbóreo. Al final del anterior apartado ya dejamos entrever el importante papel que juegan los mitos tal y como nos comenta Platón y es que este relato que nos documentan Heródoto, Hecateo de Abdera o Diodoro, por decir algunos historiadores que desarrollan en sus escritos este logos hiperbóreo, está construido gracias a dos elementos de temática parecida pero, al fin y al cabo, de distinto significado. Quiero decir que este excurso está conformado por elementos míticos y por elementos utópicos. Las características utópicas que permiten a estos hiperbóreos llevar una plácida vida y rendirle culto a divinidades como Apolo ya las hemos analizado. Ahora, analizaremos los elementos míticos que conforman esta narración.

Dichos elementos podemos relacionarlos con una especie de mito escapista y etiológico que sirve, tal vez, para poder explicar los cambios de estación siendo Apolo una especie de dios "relojero" o, incluso, para esclarecer el drástico paso de una civilización agraria a una civilización urbana. El papel de Apolo en este mito es muy importante, pues funciona como bisagra de ambos mundos: el real y el de estos descendientes de Bóreas. Además, el propio dios legislará para este pueblo (Grimal, 1981) convirtiéndose de esta forma en una especie de héroe legislador y civilizador cómo hemos señalado anteriormente.

En cuanto al drástico paso entre una comunidad agraria a otra urbanita, me estoy refiriendo al mítico enfrentamiento entre campo-ciudad que parece ser un hecho intrínseco a la naturaleza del 
ser humano y que podemos apreciar en muchos mitos como, por ejemplo, la lucha de los dioses (urbanitas) frente a los titanes (fuerzas de la naturaleza) o en el célebre episodio bíblico entre David y Goliat.

En el territorio de este mítico pueblo, también nos encontramos con la estancia de Atlas/ Atlante, un jóven titán (una fuerza de la naturaleza) condenado a soportar la bóveda del cielo con sus propias manos (Grimal, 1981) y que puede dar un respaldo a esta hipótesis que acabo de realizar. Otro aspecto que puede sustentar las ideas mencionadas es la actividad que llevó a cabo en este hipotético país Hércules, pues cuando el héroe semi-divino griego partió a por la cierva Cerinea, pasó por este territorio, entabló amistad con los hiperbóreos y estos le dieron como regalo, tras persaudirlos durante largo tiempo, unos esquejes que luego este plantaría en la llanura de Élide que, hasta entonces, había permanecido como un terreno inhóspito donde nada podía crecer. De ahí que muchos centros panhelénicos se sintieron en deuda con este pueblo fantástico por las desinteresadas acciones que estos realizaban como estos esquejes o como las ofrendas de trigo (Romm, 1992).

De esta manera, se aprecia como todos los aspectos del ser humano se implican en la formulación del mito. Así pues, un mito es "una línea de vida, una figura de futuro antes que una fábula fósil" como indica Bachelard en el prólogo de la obra de Diel (1998, p. 8)

De la misma forma, los hiperbóreos tienen una peculiaridad respecto al resto de pueblos utópicos: un contacto directo con el mundo griego, en concreto, con Delos (que se vanagloriaba de sus antiquísimos contactos con este pueblo) y en el que se dice que fueron los propios hiperbóreos quienes introdujeron las ofrendas a Apolo y a Ártemis; y con Delfos bien a través de ofrendas ${ }^{16}$, a través de la presencia de personas de este pueblo entre los griegos como los que dice Pausanias (Descripción de Grecia, I, 4, 4) que vinieron a proteger Delfos durante la invasión de los gálatas o por el comercio de ámbar. De igual forma, el oriundo de Halicarnaso (Hdt, IV, 23) nos cuenta el rito con rasgos etiológicos que llevaban a cabo los jóvenes habitantes de Delos en honor a Hipéroca y Laódice, dos muchachas hiperbóreas que venían a realizar ofrendas a esta isla pero que la muerte no les permitió regresar a su idílico país y fueron enterradas aquí, también menciona a otra parejas de hiperbóreas de nombres Arge y Opis que llegaron acompañadas por Apolo y Artemisa (Hdt., IV, 25). Asimismo, en el caso de Olimpia, fue Heracles que en el transcurso de uno de sus trabajos, había conocido a los hiperbóreos y sus olivos ${ }^{17}$, los cuales le dieron al héroe griego unos esquejes para poder plantarlos en la llanura de la Élide.

Esta relación con un mundo "corpóreo" y real ha determinado e influido para que muchos historiadores hayan especulado que tal vez los hiperbóreos fueran un pueblo real situado a las orillas del mar Báltico o de los ríos Vístula y Óder y que fue mitificado por los griegos. Según Zecchinni, este pueblo mitificado bien pudieran ser los celtas y es que ciertos autores como Heráclides Póntico, confunde a los celtas con los hiperbóreos cuando habla de los celtas que saquearon la ciudad eterna: Roma (Marco Simón, 2000). Sin embargo, esto sería simplificar un tanto las cosas al vincular este excurso a un hecho real y tangible, además de que todos los elementos que hemos ido comentado a lo largo de este artículo no apuntan a tal sentido.

16 Unas ofrendas que como nos cuenta el historiador-geógrafo-etnógrafo de Halicarnaso, en un principio la traían parejas de hiperbóreas pero que al final, debido a que estas no regresaban, fueron pasando de mano en mano hasta llegar a su destino (Hdt, IV, 23). De esta versión también se hace eco los escritos de otros historiadores antiguos posteriores como Pausanias (Descripción de Grecia, 1.31). Ahondando en el tema de la "desaparición" de esos heraldos hiperbóreos, lo podemos poner en relación con la "contaminación" que sufrían de las personas normales que hacía que luego no pudieran volver a su tierra natal, una tierra virgen y ajena al mal terrenal.

17 Árbol que ocupa un importante y fuerte papel simbólico en las sociedades mediterráneas. Era un símbolo de victoria en los Juegos Olímpicos, era la materia prima de lo que estaba hecha el arma de Hércules, fue el regalo que hizo Atenea a Atenas cuando competía con Poseidón por el "apadrinamiento" de esta ciudad, fue la ofrenda que hizo Teseo a Apolo cuando marchó a luchar contra el minotauro, etc. Incidimos pues en el inmenso valor que tenía dicha planta como símbolo de esperanza, fuerza y regeneración. 


\section{Reflexiones finales}

Para ir finalizando el presente ensayo, deberíamos hacernos la pregunta acerca de este logos hiperbóreo que se hace Gómez Espelosín (1997, p. 466) en uno de sus artículos en referencia al logos escita presente en la obra de Heródoto: "¿reflejo de la realidad o una mera ficción camuflada hábilmente con los ropajes del procedimiento histórico?".

En mi opinión, este excurso presente en numerosos autores de la antigüedad, retrataría a modo de un "espejo de la voluntad", como diría el filósofo alemán Arthur Schopenhauer, el mundo soñado de una sociedad griega que representa unos valores diametralmente opuestos respecto a estos hombres que poblarían los confines del mundo. Esta idea de oposición diametral está muy presente en las Historias de Heródoto que concibe la naturaleza como un constante y dinámico equilibrio de fuerzas antagónicas que se regulan entre sí (Caballero López, 2010).

Retornando al objeto principal de nuestro estudio, hemos de incidir en cómo la sociedad de los hiperbóreos ejemplifica justo lo contrario de lo que estaba sucediendo en Grecia: guerras, hambrunas, tierras poco fértiles por su orografía y sus condiciones climáticas, problemas sociales que surgían en el seno de las poleis, etc. Los hiperbóreos suponían la negación de esta dura existencia comparándose, como ya he dicho anteriormente, con los hombres de la Edad de Oro de Hesíodo gracias a su vida sin trabajo, su relación con la naturaleza, sus tierras fértiles gracias a su eukrasía, su longevidad, sus relaciones con los dioses, etc. Es decir, a través del relato de un pueblo desconocido y muy lejano (situado en los confines de la ecúmene ${ }^{18}$ ), con rasgos paradisíacos como si de un Edén ${ }^{19}$ se tratara, los griegos proyectan una serie de creencias y anhelos que nos permiten conocer mejor las ideas y formas del pensamiento del griego clásico y que les aleja, como si de una válvula de escape se tratara, de la inestable vida que por capricho del destino les había tocado vivir.

Concretando, aún más, el mundo funcionaría como un lenguaje ya que habla al hombre por su propio modo de ser, por sus estructuras y sus ritmos (Eliade, 1991). Esto que hemos venido mencionando es una de las tesis principales de la afamada obra de Hartog Le miroir d'Hérodote. Essai sur la représentation de l'autre que realiza este mismo análisis del imaginario griego a través del logos escita que presenta Heródoto en su libro IV mientras que nosotros lo hemos estado haciendo de la narración del mundo hiperbóreo.

En consecuencia, el relato de los hiperbóreos es un escrito de naturaleza mítica, utópica (no siempre tienen por qué ir de la mano estos dos conceptos) y escapista, pues representaría lo contrario de lo que les tocaba vivir a los griegos, por lo tanto, tendría un fuerte componente crítico frente a la sociedad griega. Esta sociedad era vista por los autores de la época como algo corrupto e impuro que no paraba de deteriorarse, de ahí el contenido crítico y sarcástico en la elaboración de este excurso. Esta historia que hemos venido analizando nos permite conocer más a fondo el complejo imaginario del mundo griego al proyectar sus angustias y anhelos en esta sociedad.

Para concluir, hemos de decir que el concepto de "hiperbóreos" ha permanecido con su significado en el imaginario colectivo a lo largo de la historia al vincularse directamente con el propio sentimiento escapista que tienen determinadas personas y comunidades. De la misma manera es un recurso muy utilizado en distintas ideologías y creencias incluyendo la doctrina cristiana. Los

18 Lo que no hace sino favorecer su localización al ser un lugar lejano de la vida cotidiana a la que estaba sometido un griego y en el que podía proyectar las sombras de sus ideas que adquirían pues una forma concreta y real (Ferguson, 1975; Romm, 1992; Espelosín et alii, 1994; Espelosín, 2000 y Albaladejo Vivero, 2005).

19 Existe un artículo muy interesante acerca del papel que ocupan los jardines y paisajes naturales en el mundo de las creencias de la Grecia antigua. Dicho artículo es el siguiente: Martínez Hernández (2008). El jardín es un elemento más de los que conforman el complejo imaginario colectivo griego y, por tanto, su estudio como parte de este cosmos nos permite arrojar luz sobre el mundo de las mentalidades y de las creencias griegas. Nos interesa por su relación con lo visto en este estudio, su cualidad como "locus amoenus" o "paisaje ameno". 
propios escritores cristianos antiguos conocían esta concepción y, como hicieron con muchas otras, la "adoptaron" a su liturgia. Así los hiperbóreos quedaron conformados en el cosmos cristiano como un ejemplo de piedad y austeridad que todo buen cristiano debía intentar seguir e igualar para alcanzar el Reino de los Cielos (Piquero, 2011).

De la misma forma, uno de los grandes pensadores de la filosofía contemporánea, Friedrich Nietzsche, utilizó este vocablo en su terminología filosófica. El gran pensador alemán llamará hiperbóreos a aquellas pocas personas que consiguen librarse de las cadenas impuestas por la sociedad y la religión para abrazar su filosofía y llegar, en un lejano futuro, al concepto de "superhombre", de ahí, que él mismo piense que es un descendiente moral de los hiperbóreos ${ }^{20}$ aunque en su persona no se pueda aplicar el término, malentendido, de "superhombre"; él es un profeta como hace de Zaratustra en una de sus obras, no un "superhombre", un hiperbóreo a fin de cuentas. Concretando lo que dice este filósofo, define bajo este apelativo, justo lo contrario de lo que veía en la masa social de su época, produciéndose un fenómeno parecido al de la Antigüedad Clásica y es que Nietzsche, profesor de filología clásica en la Universidad de Basilea (1869-1879), tuvo que ser conocedor del verdadero significado de este vocablo y acertó a la hora de adjudicárselo para su propia filosofía.

Para nuestra desgracia, también fue utilizado por la potente maquinaria propagandística nazi con su vertiente esotérica de relacionar distintos mitos, creencias religiosas y creencias populares con el origen de esa hipotética raza superior aria a la que ellos creían pertenecer. El mito del que nos hemos ocupado humildemente en estas líneas no fue una excepción en la búsqueda de un glorioso pasado que justificara un peso político y justificativo de aquello que aspiraban a conseguir (Kater, 2006). El uso de los hiperbóreos por esas "personas" consistía en hacer ver a los alemanes que eran descendientes de este idealizado pueblo para así glorificar las raíces de Alemania pues para los mecanismos de propaganda ser ario equivalía, en cierta manera, a ser hiperbóreo (Sala Rose, 2003).

De igual forma, el concepto del mundo hiperbóreo como lugar mítico cargado de riquezas, paz y hombres superiores, no solo sedujo a la ultraderecha en Alemania. El escritor y profesor Vselovod Pavlovich Ivanov, miembro de la IAREV ${ }^{21}$, utiliza el término de Hiperbórea en sus escritos como recurso y como anhelo al referirse a un mundo al que aspira pero que, por la naturaleza humana, este anhelo, esta aspiración, es baldía pues el hombre jamás podrá alcanzar ese desarrollado estado natural y primigenio del hombre pues este se ha dejado corromper y pudrir en su espíritu y en su forma de vida por lo que ya en nada se parece a estos hiperbóreos, hombres de la Edad de Oro, los Tuatha De Danann irlandeses o cualquiera de los mitos escapistas que poseen todas y cada una de las civilizaciones que han poblado este mundo, lo que nos indica la auténtica necesidad de la creación de estos mitos y el especial lugar que ocupa en el imaginario del género humano.

\section{Bibliografía}

Albaladejo Vivero, M. (1998). Los hiperbóreos, "benefactores" de Grecia. Polis. Revista de ideas y formas políticas de la Antigüead Clásica, 10, 5-28.

20 Entre todos las referencias que hace el erudito alemán a los hiperbóreos en su obra, hemos decidido reseñar al respecto la muy interesante cita que nos muestra en su póstuma obra El anticristo (p. 19) cuando indica: "Examinemos con minuciosidad. Somos hiperbóreos; vivimos eternamente separados, y tenemos conciencia de nuestra separación. "iNi por mar ni por tierra hallarás el camino que conduce al país de los eternos hielos!» Píndaro lo ha dicho por nosotros. Más allá del norte, los hielos y la muerte, nuestra vida, nuestra felicidad. Hemos descubierto la dicha; conocemos el sendero que conduce a ella; hemos encontrado la salida a través de millares de años". Podemos observar, a través de este fragmento, la forma en la que se pone en relevancia lo que hemos venido comentando, es decir, la manera en la que el filósofo alemán define a los hiperbóreos como aquellas personas que han abrazado su filosofía desprendiéndose de lo que él mismo definió como "enfermedad del modernismo".

21 Asociación Internacional de Escritores Revolucionarios del Esperanto. 
Albaladejo Vivero, M. (2005). Los extremos de Europa en la obra de Píndaro y de Heródoto. Klio 87.2, 315-328.

Bolton, J. D. P. (1999 [original 1962]). Aristeas of Proconnesus. Oxford: Clarendon Press.

Caballero López, J. A. (2010). Inicios y desarrollo de la Historiografía griega. Madrid: Síntesis.

Diel, P. (1998). El simbolismo en la mitología griega. Rosellón: Idea Universitaria.

Díez de Velasco, F. (2010). El agua en el viaje de la muerte en la Grecia antigua: identidad y memoria. En Fornis, C. y otros (eds.), Dialéctica histórica y compromiso social. Homenaje a Domingo Plácido (pp. 1295-1307). Zaragoza: Libros Pórtico.

Dion, R. (1976). La notion d'Hyperboréens. Ses vicissitudes au cours de l'Antiquité. Bulletin de l'Association Guillaume Budé, 2, 143-157.

Eliade, M. (1991). Mito y realidad. Barcelona: Laboral.

Eliade, M. (1998). Historia de las creencias religiosas (I): de la edad de piedra a los misterios de Eleusis. Barcelona: Paidos.

Ferguson, J. (1975). Utopias of the Classical World. Londres: Cornell University Press.

García Sánchez, M. (2009). El gran rey de Persia. Formas de representación de la alteridad persa en el imaginario griego. Barcelona: Universidad de Barcelona.

Gómez Espelosín, F. J., Guzmán Guerra, A. y Guzmán Garáte, I. (2005). Grecia. Mito y memoria. Madrid: Alianza.

Gómez Espelosín, F. J.; Pérez Largacha, A. y Vallejo Girvés, M. (1994). Tierras fabulosas de la Antigüedad. Alcalá de Henares: Servicio de publicaciones de la Universidad de Alcalá de Henares.

Gómez Espelosín, F. J. (1997). Más allá de la polis. A la búsqueda de espacios ideales. En Plácido, D., Alvar, J., Casillas, J. M. y Fornis, C. (eds.), Imágenes de la Polis (pp. 451-467). Madrid: Ediciones Clásicas.

Gómez Espelosín, F. J. (2000). El descubrimiento del mundo. Geografía y viajeros en la antigua Grecia. Madrid: Akal.

Graves, R. (1985). Los Mitos griegos. Madrid: Ariel.

Grimal, P. (2009). Diccionario de Mitología Griega y Romana. Barcelona: Paidós lbérica.

Harmatta, J. (1957). Sur l'origine du mythe des Hyperboréens. Acta Antiqua Academiae Scientiarum Hungaricae, 3, 57-64.

Hartog, F. (1980). Le miroir d'Hérodote. Essai sur la représentation de l'autre. París: Gallimard. Bibliothèque des histoires.

Jacoby, F. (1958-1969). Die Fragmente der griechischen Historiker. Leiden: Brill.

Kater, M. H. (2006). Das "Ahnenerbe" der SS, 1935-1945: Ein Beitrag zur Kulturpolitik des Dritten Reiches. München: Oldenbourg Wissenschaftsverlag.

Lens Tuero, J. y Campos Daroca, J. (2000). Utopías del mundo antiguo. Antología de textos. Madrid: Alianza.

Marco Simón, F. (2000). Eschatoi andrôn: la idealización de Celtas e Hiperbóreos en las fuentes griegas. Dialogues d'histoire ancienne, 26/2, 121-47.

Martínez Hernández, M. (2008). Descripciones de jardines y paisajes en la literatura griega antigua. Cuadernos de Filología Clásica: Estudios griegos e indoeuropeos, 18, 279-318.

Martínez Hernández, M. (2010). Islas míticas en relación con Canarias. Cuadernos de Filología Clásica: Estudios griegos e indoeuropeos, 20, 139-158.

Peyras, J. (1995). L' île et le sacré dans l'Antiquité. En Marimoutou, J. C. y Racault, J. J., L'insularité. Thémathique et représentations. Actes du colloque International de Saint-Denis de la Réunion, avril 1992 (pp. 27-35). París: L'Harmattan.

Piquero Rodríguez, J. (2011). El mito de los hiperbóreos en la obra de Hecateo de Abdera. En Multa Movens Animo. Actas del I Encuentro de Jóvenes Investigadores en Filología Clasíca (pp. 6774). Madrid: UAM Ediciones.

Piquero Rodríguez, J. (2012). Los hiperbóreos: mito y religión. Cuadernos de Filología Clásica: Estudios griegos e indoeuropeos, 22, 109-122. 
Rohde, E. (1973). Psique. La idea del alma y la inmortalidad entre los griegos. México: Fondo de cultura económica.

Romm, J. (1992). The edges of the earth in ancient thought: geography, exploration, and fiction. Princeton: University Press.

Rudhart, J. (1971). Le thème de l'eau primordiale dans la mythologie grecque. Berna: Editions Francké.

Sala Rose, R. (2003). Diccionario crítico de mitos y símbolos del nazismo. Barcelona: El Acantilado. Vernant, J. P. (1992). Los orígenes del pensamiento griego. Barcelona: Paidos.

Vilatte, S. (1991). L'insularité dans la pensée grecque. París: Les belles lettres.

\section{Fuentes}

Diodoro Sículo. Biblioteca Histórica. Madrid: Gredos. 2001 [Introducción, traducción y notas de Francisco Parreu].

Estrabón. Geografía. Libros VIII-X. Madrid: Gredos. 2001 [Traducción y notas por Juan José Torres Esbarranch].

Herodoto. Historias, Libros III- IV. Madrid: Gredos. 1995 [Traducción y notas de Carlos Scharader].

Hesíodo. Trabajos y días. Madrid: Gredos. 1983. [Traducción de Aurelio Pérez Jiménez y Alfonso Martínez Díez].

Homero. Odisea. $2^{a}$. edición. Barcelona: Planeta. 1973. [Introducción y notas de José Alsina]. Traducción en verso de Fernando Gutiérrez].

Friedrich Nietzsche. El anticristo. Barcelona: Fontana. 2012. [Traducción de Enrique Eidelstein y, Prólogo y presentación de Francesc LL. Cardona].

Tomás Moro. Utopía. Edimat libros. 2008 [Estudio preliminar elaborado por Enrique López Castellón] Pausanias. Descripción de Grecia. Madrid: Alianza. 2000. [Introducción, trad. y notas de Camino Azcona García].

Platón. República. Madrid: Gredos. 1986. [Introducción, traducción y notas de Conrado Eggers Lan].

Pindaro. Odas: Olímpicas, Píticas, Nemeas e Ítsmicas. México: Bibliotheca Scriptorum Graecorum et Romanorum Mexicana. Pindaroy Epinikia. 2005. [introducción, versión rítmica y notas de Rubén Bonifaz Nuño].

Plinio. Historia Natural. Madrid: Gredos. 1995-2010 [Introducción general Guy Serbat; Traducción y notas de Antonio Fontán, Ana M. ${ }^{a}$ Moure y otros]. 



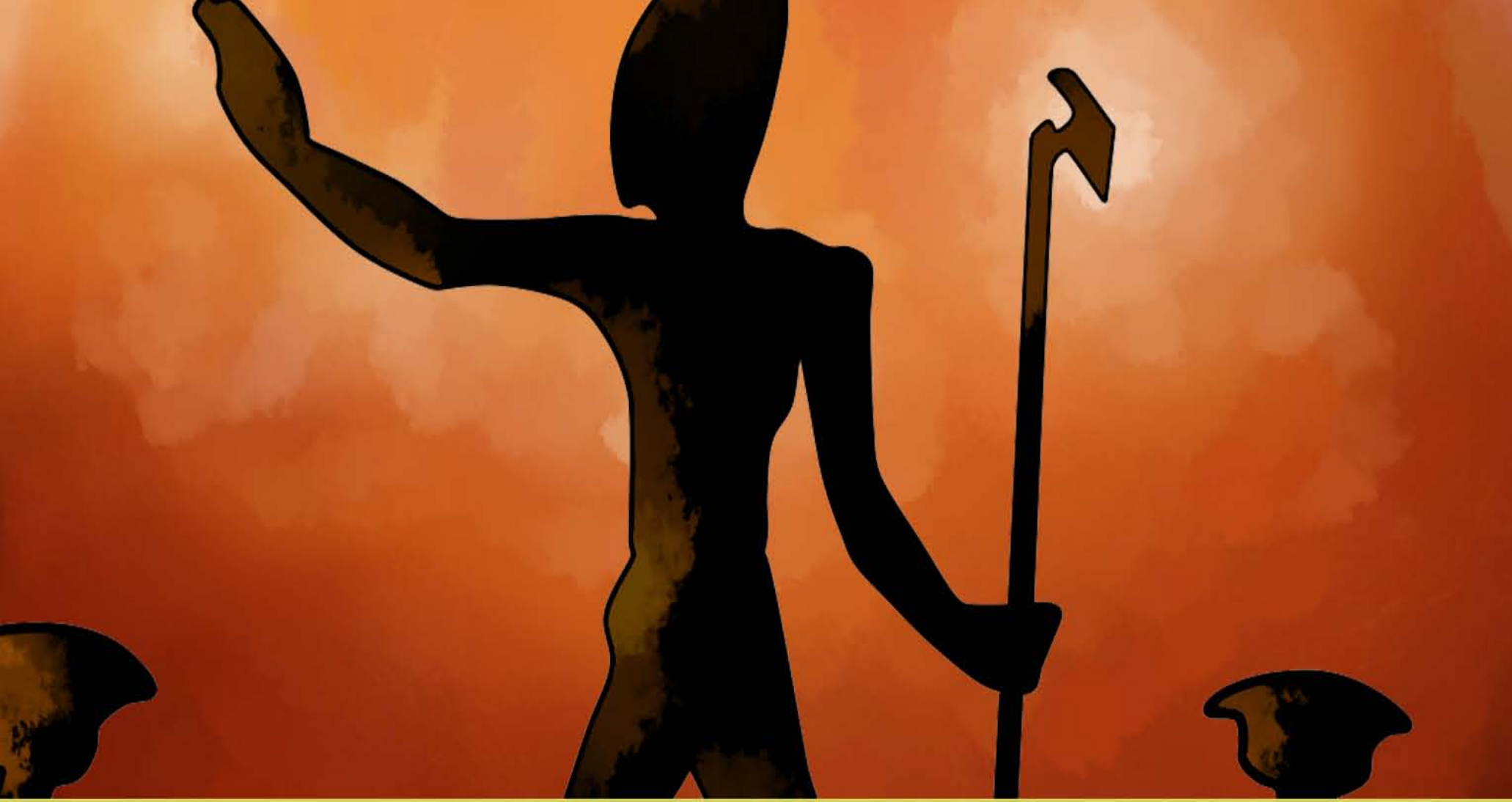

